\title{
Simultaneous determination of ten taste and odor compounds in drinking water by solid-phase microextraction combined with gas chromatography-mass spectrometry
}

\author{
Xichao Chen, Qian Luo*, Shengguang Yuan, Zi Wei, Hanwen Song, Donghong Wang, Zijian Wang \\ State Key Laboratory of Environmental Aquatic Chemistry, Research Center for Eco-Environmental Sciences, Chinese Academy of Sciences, Beijing \\ 100085, China. E-mail: 06xichao@163.com
}

Received 11 January 2013; revised 25 March 2013; accepted 28 March 2013

\begin{abstract}
Taste and odor $(\mathrm{T} \& \mathrm{O})$ problems in drinking water frequently occur because of many compounds present in the water, of which trans1,10-dimethyl-trans-9-decalol (geosmin) and 2-methylisoborneol (MIB) are well-known. In this study, a fast and effective method was established for simultaneous determination of $10 \mathrm{~T} \& \mathrm{O}$ compounds, including geosmin, MIB, 2,4,6-trichloroanisole (TCA), 2methylbenzofuran, 2-isopropyl-3-methoxypyrazine (IPMP), 2-isobutyl-3-methoxypyrazine (IBMP), cis-3-hexenyl acetate, trans,trans2,4-heptadienal, trans, cis-2,6-nonadienal, and trans-2-decenal in water samples by headspace solid-phase microextraction (SPME) coupled with gas chromatography-mass spectrometry. An orthogonal array experimental design was used to optimize the effects of SPME fiber, extraction temperature, stirring rate, $\mathrm{NaCl}$ content, extraction time, and desorption time. The limits of detection ranged from 0.1 to $73 \mathrm{ng} / \mathrm{L}$ were lower than or close to the odor threshold concentrations (OTCs). All the $10 \mathrm{~T} \& \mathrm{O}$ compounds were detected in the 14 water samples including surface water, treatment process water and tap water, taken from a waterworks in Lianyungang City, China. MIB and geosmin were detected in most samples at low concentration. Six T\&O compounds (IPMP, IBMP, trans,cis-2,6nonadienal, 2-methylbenzofuran, trans-2-decenal, and TCA) were effectively decreased in water treatment process (sedimentation and filtration) that is different from cis-3-hexenyl acetate, MIB and geosmin. It is noted that the TCA concentrations at $15.9-122.3 \mathrm{ng} / \mathrm{L}$ and the trans,cis-2,6-nonadienal concentrations at 79.9-190.1 ng/L were over 10 times higher than their OTCs in tap water. The variation of the analytes in the all water samples, especially distribution system indicated that distribution system cannot be ignored as a $\mathrm{T} \& \mathrm{O}$ compounds source.
\end{abstract}

Key words: taste and odor compound; drinking water; SPME-GC/MS; geosmin; 2,4,6-trichloroanisole

DOI: $10.1016 / \mathrm{S} 1001-0742(12) 60290-3$

\section{Introduction}

Taste and odor (T\&O) compounds are troublesome in water supplies in many parts of the world because they dramatically impact the acceptability of the drinking water to the consumers (Sung et al., 2005; Deng et al., 2011). Geosmin (earthy) and 2-methylisoborneol (MIB) (musty) have been identified as major $\mathrm{T} \& \mathrm{O}$ compounds in drinking water from surface water sources, and mainly result from the metabolism and biodegradation of certain types of microorganisms (Peter et al., 2009). Conventional water treatment processes such as chlorination, coagulation and sedimentation are ineffective for removal of MIB and geosmin (Srinivasan and Sorial, 2011) and other T\&O compounds like trans, trans-2,4-heptadienal (fishy) (Wat-

\footnotetext{
* Corresponding author. E-mail: qianluo@ rcees.ac.cn
}

son et al., 2001). In addition, T\&O compounds could be produced during water treatment processes and/or from the water distribution network (Proulx et al., 2012). Previously, most studies focusing on T\&O compounds have been limited to earthy and musty compounds, including MIB, geosmin, 2-isopropyl-3-methoxypyrazine (IPMP), 2-isobutyl-3-methoxypyrazine (IBMP) and 2,4,6trichloroanisole (TCA). These compounds can easily cause $\mathrm{T} \& \mathrm{O}$ problems in lakes and reservoirs because of their extremely low odor threshold concentrations (OTCs) (Palmentier and Taguchi, 2001; Sun et al., 2012). Few studies have investigated other off-flavors such as the unsaturated aldehydes trans, trans-2,4-heptadienal, trans, cis-2,6nonadienal (grassy) and trans-2-decenal (sweet) that are produced by algae and/or fish in natural aquatic environments (Hartvigsen et al., 2000; Watson et al., 2001). cis-3-Hexenyl acetate (grassy) is an odor compound de- 
rived from decaying grass (Suffet et al., 2004), and 2-methylbenzofuran (smoky) has been identified as an odorant in cereal grains (Magan and Evans, 2000) and raw scallops (Morita and Aishima, 2002). There are currently no regulations for $\mathrm{T} \& \mathrm{O}$ compounds even the most common geosmin and MIB only with reference concentrations in the Standards for Drinking Water Quality (GB57492006), partly because they have not been associated with immediate health effects (Srinivasan and Sorial, 2011).

There are several reports on the occurrence of sulfur T\&O compounds in natural waters. Concern increased after a water crisis in Wuxi, China in 2007 that was caused by an algal bloom in Taihu Lake that affected the aesthetic qualities of the water (Yang et al., 2008; Zhang et al., 2010). Dimethyl trisulfide and related alkyl sulfide compounds, but not MIB and geosmin, were the key odorcausing compounds in this incident (Yang et al., 2008; Yu et al., 2009). Therefore, more T\&O compounds should be concerned and detected. In a study of cyanobacterial blooms in Midwest lakes in the USA, toxins and T\&O compounds co-occurred frequently, which indicates that odor may serve as a warning that harmful toxins are present (Graham et al., 2010). The OTCs of T\&O compounds are at ng/L level or even less (Zhang et al., 2005; Salemi et al., 2006). Because sensitivity to these compounds can vary among people and even in one person with time, it is not possible to determine an exact concentration or a very restricted concentration range for the OTCs.

Sensory gas chromatography coupled to mass spectrometry (GC/MS) analysis was used for the simultaneous identification of trace organics and description of their odors (Young et al. 1999; Yu et al., 2009). However, GC/MS is not sensitive enough to measure very small amounts of $\mathrm{T} \& \mathrm{O}$ compounds without enrichment (Godayol et al., 2011). To date, a wide variety of extraction and enrichment techniques, including closed-loop stripping (Malleret et al., 2001), purge and trap (P\&T) (Chen et al., 2010a), membrane-based extraction (Zander and Pingert, 1997) and stir bar sorptive extraction (Ochiai et al., 2001) have been established and applied to some T\&O compounds. Some of these methods have poor sensitivity, while some are time-consuming and labor-intensive (Deng et al., 2011). The stability and durability of solidphase microextraction (SPME) limit its wider application although as a popular sample preparation technique (Sun et al., 2012). Choosing a fiber suitable for the simultaneous analysis of odorants is also difficult because of the wide polarity and volatility ranges of the analytes (Deng et al., 2011). In earlier studies, a number of one-factor-at-a-time experiments were conducted to investigate individual factors (Watson et al., 2000; Sung et al., 2005). However, this strategy overlooks interactions among the factors (George et al., 2004). Six of the SPME factors including extraction temperature, extraction time, desorption time, stirring rate, $\mathrm{NaCl}$ content, and fiber coating have an impact on their enrichment. An orthogonal array experimental design (OAD) is an alternative way that can be used to overcome this limitation.

In the present study, an analytical method was developed for simultaneous quantification of $10 \mathrm{~T} \& \mathrm{O}$ compounds from different chemical families in water samples. The SPME-GC/MS method was applied to investigate occurrence and concentrations of $10 \mathrm{~T} \& \mathrm{O}$ compounds in water samples. The species and concentrations of $\mathrm{T} \& \mathrm{O}$ compounds were simultaneously analyzed in raw water, the water treatment processes (sedimentation, filtration and ozone) and tap water in plant adopting chlorine as disinfectant. Possible factors influencing the production of and/or decreases in $\mathrm{T} \& \mathrm{O}$ compounds are also discussed based on investigation of water treatment plants in representative north city (Lianyungang) that employ typical disinfection methods in China.

\section{Materials and methods}

\subsection{Chemicals}

Geosmin, MIB, TCA, IPMP, IBMP, 2-methylbenzofuran, cis-3-hexenyl acetate, trans,cis-2,6-nonadienal, trans,trans-2,4-heptadienal and trans-2-decenal standards were purchased from AccuStandard (New Haven, CT, USA). The details for these compounds are given in Table S1. Methanol (HPLC grade) was acquired from Fisher Scientific (Fair Lawn, NJ, USA). Milli-Q water was obtained from a Milli-Q Plus water purification system (Millipore, Billerica, MA, USA). Stock standard solutions were prepared by weight and stored at $4^{\circ} \mathrm{C}$. Working solutions were made daily by diluting the standard solutions to the required concentrations with Milli-Q water.

\subsection{Sample collection and preparation}

Sampling was performed in the city of Lianyungang, China, in June, 2012. Surface water, treatment process water, and tap water were collected in $40 \mathrm{~mL}$ amber glass bottles with polytetrafluoroethylene-lined caps. The samples were stored at $4^{\circ} \mathrm{C}$ after collection and then analyzed within 14 days. The water qualities of these samples are summarized in Table S2. Surface water samples (a) to $(\mathrm{g})$ were collected along the Qiangwei River, which is the water source for the third water treatment plant (Lianyungang, China). The suspended solid particles on the filter membrane for these samples gave off a light fishy smell. Treatment process water samples were collected from settled water (h), filtered water (i), ozonated water (j) and finished water (k). No suspended solid particles or obvious smells were detected for these samples. Tap water samples were collected from the taps of customers supplied by the third water treatment plant. These samples (l) to (n) were collected along the pipeline from upstream to downstream. 


\subsection{Solid-phase microextraction procedure}

SPME experiments were performed with a manual fiber holder. Because the molecular weights (MW) of the analytes were between 110 and 211.5, we tested the following commercially available SPME fibers: polydimethylsiloxane (PDMS, $100 \mu \mathrm{m}, \mathrm{MW}$ 60-275), PDMS/divinylbenzene (PDMS/DVB, $65 \mu \mathrm{m}$, MW 50300), polyacrylate (PA, $85 \mu \mathrm{m}, \mathrm{MW} 80-300$ ), carboxen/PDMS, (CAR/PDMS, $75 \mu \mathrm{m}$, MW 30-225), and DVB/CAR/PDMS (2 cm-50/30 $\mu \mathrm{m}$, MW 40-275). The fiber holder and coatings were supplied by Supelco (Bellefonte, PA, USA). Before use, each fiber was exposed to a splitless/split injection port of GC under helium flow and conditioned for the recommended time at recommended temperatures according to the manufacturer's instructions to remove contaminants and stabilize the solid phase.

Sample vials $(15 \mathrm{~mL})$ with magnetic stirring bars were filled with aliquots of standard solution containing the 10 analytes or sample solution $(10 \mathrm{~mL})$. The vials were tightly capped with a polypropylene cap with hole and a polytetrafluoroethylene/silicone septum. The SPME fiber was then exposed to the headspace. A hot plate/stirrer (Corning, NY, USA) was used to maintain a constant temperature and a constant stirring rate. When the extraction was complete, the fiber was immediately introduced into the GC injection port for desorption at $270^{\circ} \mathrm{C}$. To select the best SPME fiber, the extraction process was conducted at $65^{\circ} \mathrm{C}$ for $30 \mathrm{~min}$ with constant stirring at $700 \mathrm{r} / \mathrm{min}$.

\subsection{Orthogonal array design for solid-phase microex- traction}

An OAD was used to optimize the parameters that could affect the performance of the SPME experiment. The following five variables were selected for optimization of HS-SPME regardless of interactions: (1) extraction temperature; (2) extraction time; (3) desorption time; (4) stirring rate; and (5) $\mathrm{NaCl}$ content. A four-level $\mathrm{L}_{16}\left(4^{5}\right)$ orthogonal array with repeated observations was employed to assign the five variables. The total peak area for 2-methylbenzofuran, cis-3-hexenyl acetate, trans,trans2,4-heptadienal, IPMP, and trans-2-decenal was used as Group 1, while the total peak area for MIB, IBMP, TCA trans,cis-2,6-nonadienal, and geosmin was used as Group 2. Table S3 illustrates the assignments of the experimental factors and levels for the 16 experimental trials.

\subsection{Instrumentation}

GC/MS analysis was performed on an Agilent 6890 series GC system coupled with a 5975 series mass selective detector. DB-5MS column $(30 \mathrm{~m} \times 0.25 \mathrm{~mm}$ i.d., 0.25 $\mu \mathrm{m}$ film thickness) and DB-FFAP column $(30 \mathrm{~m} \times 0.25$ $\mathrm{mm}$ i.d., $0.25 \mu \mathrm{m}$ film thickness) were purchased from Agilent Technologies, Santa Clara, CA, USA. GC was operated under the following conditions: splitless injection temperature, $270^{\circ} \mathrm{C}$; total flow rate, $52.4 \mathrm{~mL} / \mathrm{min}$; column flow rate, $1.0 \mathrm{~mL} / \mathrm{min}$; and oven temperature program, $50^{\circ} \mathrm{C}$ for $6 \mathrm{~min}$, ramped at $25^{\circ} \mathrm{C} / \mathrm{min}$ to $200^{\circ} \mathrm{C}$, and held for $3 \mathrm{~min}$. The quadrupole mass spectrometer was equipped with an electron ionization source at $70 \mathrm{eV}$ and operated as follows: ion source temperature, $230^{\circ} \mathrm{C}$; transfer line temperature, $280^{\circ} \mathrm{C}$; and solvent delay time, $6 \mathrm{~min}$. The ions used for selected ion mode are optimized. The LOD was calculated at a signal-to-noise ratio of $3(\mathrm{~S} / \mathrm{N}>3)$.

\section{Results and discussion}

\subsection{Influence of solid-phase microextraction fiber con- ditions}

The fiber coating is a critical factor for SPME, but the number of commercially available fiber coatings is limited (Li et al., 2008; Chen et al., 2010b). The coatings used in the present study covered a wide polarity range and included non-polar (PDMS), semi-polar (PDMS/DVB), polar (PA), and bipolar (CAR/PDMS and DVB/CAR/PDMS) coatings. All the five commercially available coatings were tested for simultaneous extraction of the $10 \mathrm{~T} \& \mathrm{O}$ compounds. The coating thickness also has an effect on the extraction efficiency. Lower molecular weight or volatile compounds usually require a thicker fiber coating, and larger molecular weight or semi-volatile compounds are more effectively extracted with a thinner coating. For GC use, there is only one coating thickness commercially available for PA, PDMS/DVB and DVB/CAR/PDMS. However, there are multiple coating thicknesses available for PDMS (100 $\mu \mathrm{m}$, MW 60-275; $30 \mu \mathrm{m}$, MW 80-500; 7 $\mu \mathrm{m}, 125-600)$ and CAR/PDMS (75 $\mu \mathrm{m}$, MW 30-225; 85 $\mu \mathrm{m}, \mathrm{MW} 30-225)$. According to the polarities and molecular weights of the analytes, the relatively thicker coating for PDMS (100 $\mu \mathrm{m}, \mathrm{MW}$ 60-275) and thinner coating for CAR/PDMS (75 $\mu \mathrm{m}$, MW 30-225) were selected. An initial five-level $\mathrm{L}_{25}\left(5^{6}\right) \mathrm{OAD}$ was conducted with factors of extraction temperature, extraction time, desorption time, stirring rate, $\mathrm{NaCl}$ content, and fiber coating. Results indicated that only the type of fiber coating was a highly significant factor $(P \leqslant 0.001)$, while the others were not significant $(P \geqslant 0.01)$, and this confirmed that the choice of SPME coating is a key factor for determination of T\&O compounds. Therefore, fibers were optimized individually and the other five factors were evaluated later. The bipolar coatings (CAR/PDMS and DVB/CAR/PDMS) gave higher extraction efficiencies than the single-polarity coatings PDMS, PDMS/DVB and PA (Fig. 1).

The two bipolar coatings behaved similarly. In particular, the efficiencies of both coatings for MIB were almost identical. The main difference was that the signal responses of the DVB/CAR/PDMS fiber were much higher than those for the other fiber, except for the MIB signal. This was expected because the outer $50 \mu \mathrm{m}$ layer of DVB provides capacity for larger molecules or semi-volatile compounds (Gioacchini et al., 2005). By contrast, the inner 


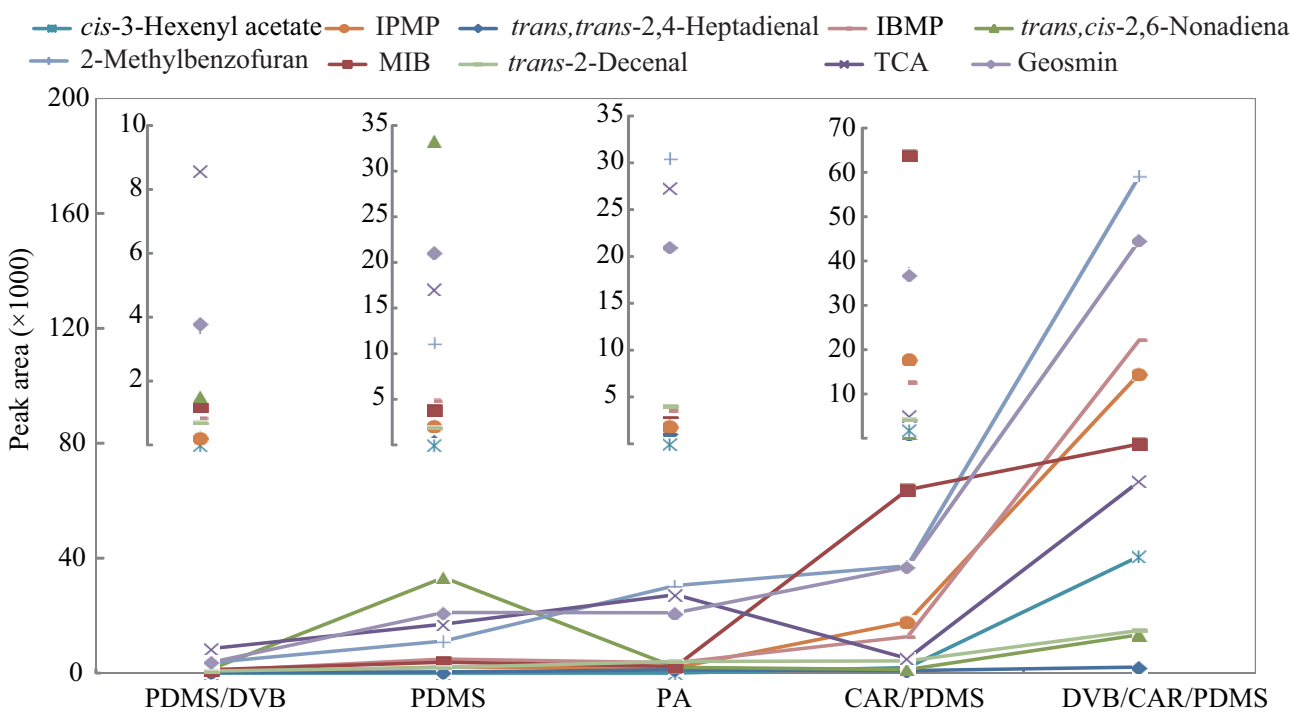

Fig. 1 Relative extraction efficiencies of 10 taste and odor analytes with five commercial fibers (PDMS, PDMS/DVB, PA, CAR/PDMS, and DVB/CAR/PDMS).

layer of CAR in DVB/CAR/PDMS was thinner (30 $\mu \mathrm{m}$ vs. $75 \mu \mathrm{m})$ than the layer in CAR/PDMS, which enhanced the extraction efficiency of the former fiber for semivolatiles. Thus, the DVB/CAR/PDMS fiber was the most suitable for simultaneous determination of the 10 semivolatile analytes. This was consistent with a previous study that indicated DVB/CAR/PDMS was the best fiber for five frequently reported $\mathrm{T} \& \mathrm{O}$ compounds (geosmin, MIB, TCA, IPMP and IBMP) (Sung et al., 2005). The present study expanded the fiber to another five compounds. Interestingly, these five frequently reported compounds clustered with relatively higher responses (Fig. 1). 2Methylbenzofuran behaved similarly to these compounds because they all contain a ring structure. However, the $2 \mathrm{~cm}-50 / 30 \mu \mathrm{m}$ DVB/CAR/PDMS fiber showed lower affinity for aliphatic compounds (cis-3-hexenyl acetate, trans,cis-2,6-nonadienal, trans,trans-2,4-heptadienal and trans-2-decenal). For the three unsaturated aliphatic aldehydes, this can be explained by high polarity and reactivity of carbonyl compounds in water matrices, which makes derivatization necessary before their detection by chromatographic techniques (Cancho et al., 2002). Consequently, although the response of the $100 \mu \mathrm{m}$ PDMS fiber for trans,cis-2,6-nonadienal was slightly higher, the $2 \mathrm{~cm}$ -
50/30 $\mu \mathrm{m}$ DVB/CAR/PDMS fiber was the best candidate for further optimization for all the analytes. Moreover, this fiber had higher affinity for cyclic compounds than aliphatic ones. For similar ring-structured T\&O compounds such as $\beta$-ionone (Peter et al., 2009), 2,4,6-tribromoanisole (Malleret et al., 2001), the method is expected to be easily expanded to incorporate more compounds.

\subsection{Optimized experimental conditions using a four- level $\mathrm{L}_{16}\left(4^{5}\right)$ orthogonal array}

The factors influencing SPME efficiency, including extraction temperature, extraction time, desorption time, stirring rate, and $\mathrm{NaCl}$ content, were investigated. The data obtained from the four-level $\mathrm{L}_{16}\left(4^{5}\right)$ OAD were evaluated by range analysis (Fig. 2) and ANOVA (Table 1). The extraction temperature, stirring rate, and $\mathrm{NaCl}$ content were highly significant at $P \leqslant 0.001$, whereas desorption time was significant at $P \leqslant 0.01$. The extraction time was less significant (only $P \leqslant 0.05$ ) within the studied range. As discussed above, the six cyclic compounds (2-methylbenzofuran, geosmin, MIB, TCA, IPMP and IBMP) showed higher responses than the four aliphatic ones (cis-3-hexenyl acetate, trans,cis-2,6-nonadienal, trans,trans-2,4-heptadienal and trans-2-decenal). There-

Table 1 Results of the $\mathrm{L}_{16}\left(4^{5}\right)$ orthogonal array for factors influencing SPME

\begin{tabular}{lllll}
\hline Source & Sum of squares & Degrees of freedom & Mean squares & $F$ \\
\hline Ext. temp. $^{\mathrm{b}}$ & $3.174 \times 10^{13}$ & 3 & $1.058 \times 10^{13}$ & 107.551 \\
Ext. time $^{\mathrm{c}}$ & $1.197 \times 10^{12}$ & 3 & $3.990 \times 10^{11}$ & 4.055 \\
Desorb. time $^{\mathrm{d}}$ & $2.073 \times 10^{12}$ & 3 & $6.910 \times 10^{11}$ & 7.024 \\
Stirring rate & $6.222 \times 10^{12}$ & 3 & $2.074 \times 10^{12}$ & $0.025^{*}$ \\
NaCl & $6.949 \times 10^{12}$ & 3 & $2.316 \times 10^{12}$ & $0.003^{* *}$ \\
Error & $1.574 \times 10^{12}$ & 16 & $9.838 \times 10^{12}$ & 23.080 \\
Total & $1.995 \times 10^{14}$ & 32 & & $0.000^{* * *}$ \\
\end{tabular}

a $*, * *$ and $* * *$ significant at $P \leqslant 0.05, P \leqslant 0.01$ and $P \leqslant 0.001$, respectively; ${ }^{\mathrm{b}}$ Ext. temp.: extraction temperature; ${ }^{\mathrm{c}}$ Ext. time: extraction time; ${ }^{\mathrm{d}}$ Desorb. time: eesorption time. 


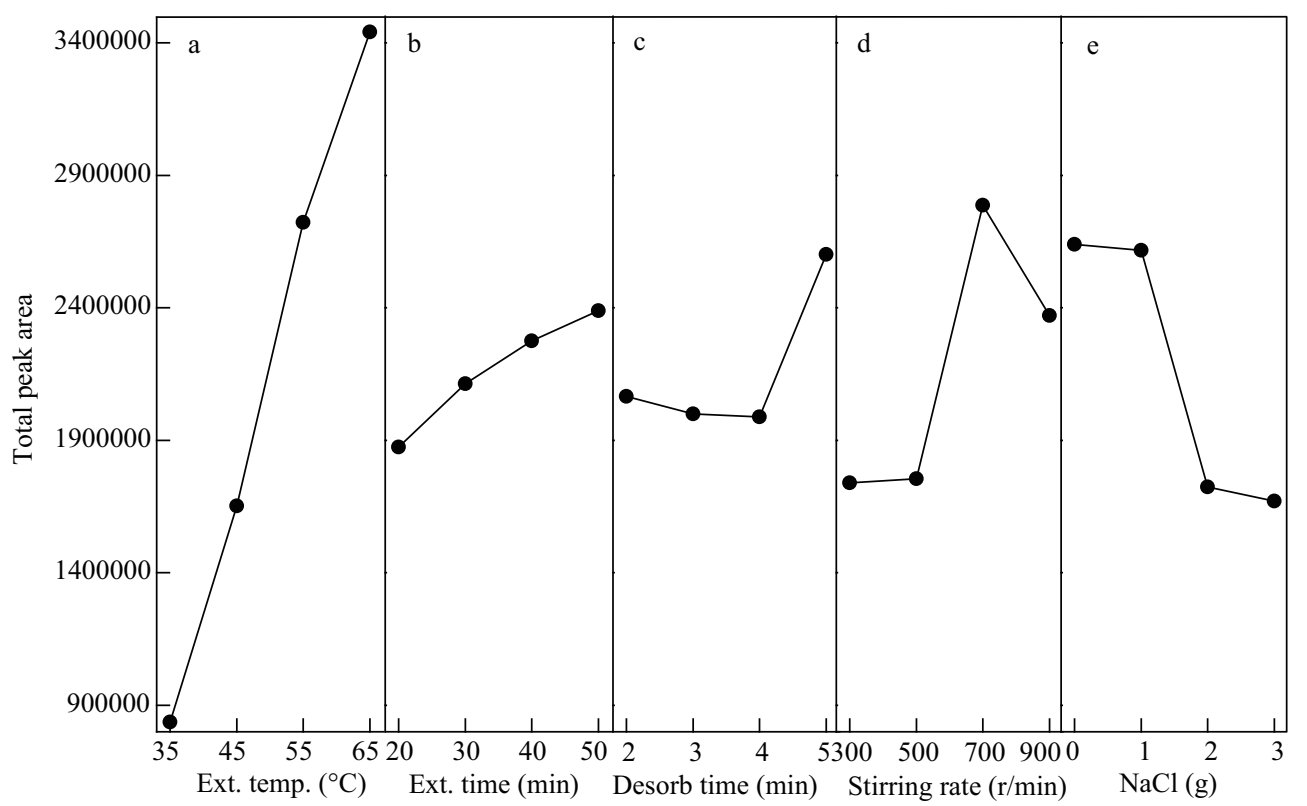

Fig. 2 Profiles of the total peak areas obtained in the range analysis of the orthogonal array. (a) extraction temperature; (b) extraction time; (c) desorption time; (d) stirring rate; (e) salt content.

fore, in the four-level $\mathrm{L}_{16}\left(4^{5}\right) \mathrm{OAD}$, it is important to optimize these four aliphatic compounds for a simultaneous determination method even if compromises are made with the responses of the other six compounds. To optimize the experimental conditions, both the total peak area and the individual areas of the four aliphatic compounds were considered.

The extraction temperature was a crucial variable for SPME of T\&O compounds since it had a noticeable influence on the target analytes as shown by the ANOVA results in Table 1. It has been reported that high temperature can have undesirable effects on the extraction efficiency of SPME fibers for some low molecular weight analytes with higher volatility because adsorption of analytes by the fiber coating is an exothermic process (Fang et al., 2003; Burbank and Qian, 2005; Vichi et al., 2005). However, in this study, a definite increase in total peak area occurred when the temperature increased from 35 to $65^{\circ} \mathrm{C}$ (Fig. 2a). The four aliphatic compounds showed similar trends (Fig. 3a). This is because migration from the solution to the headspace phase predominates for the semi-volatile analytes at the studied temperature range (Godayol et al., 2011). Moreover, higher temperature decreases the time to reach equilibrium. Although $65^{\circ} \mathrm{C}$ was not the equilibrium

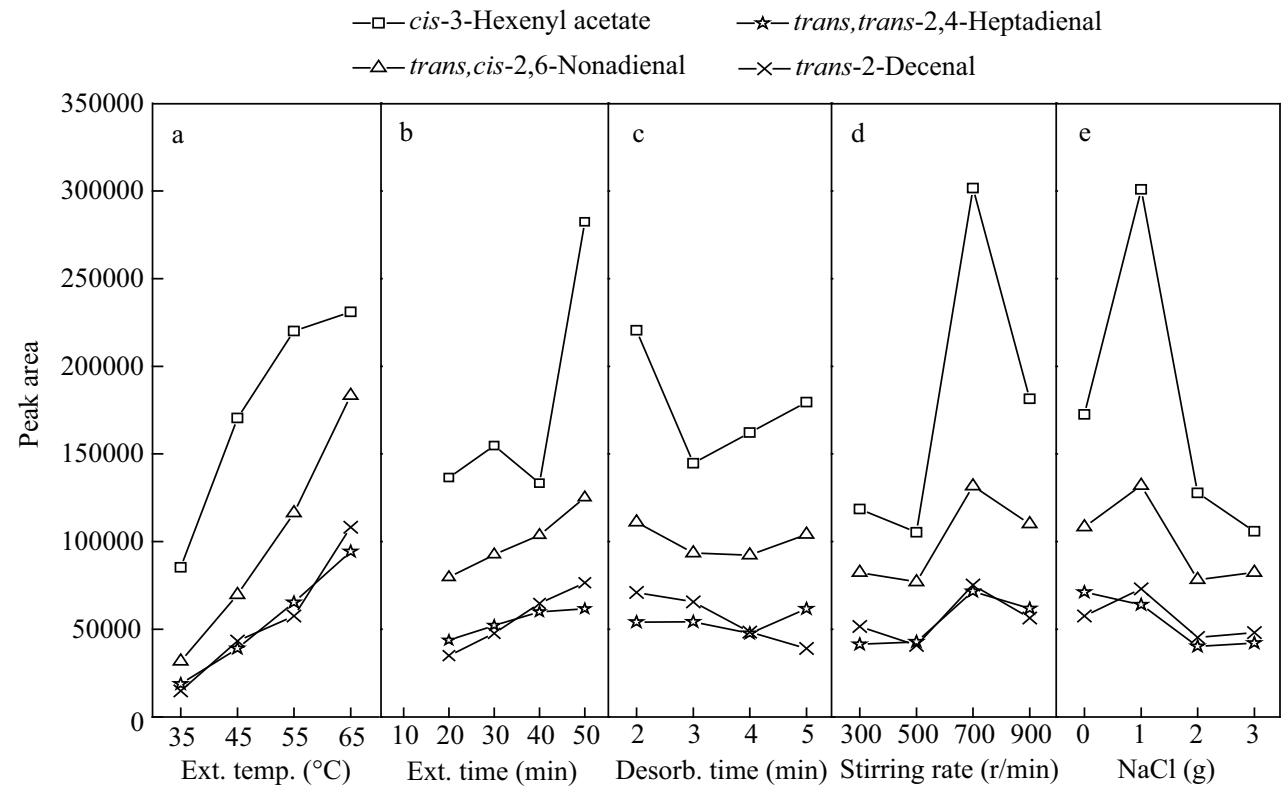

Fig. 3 Profiles of the four aliphatic analytes with low responses. (a) extraction temperature; (b) extraction time; (c) desorption time; (d) stirring rate; (e) salt content. 
temperature, it was close to it. Saito et al. (2008) found that $70^{\circ} \mathrm{C}$ was the optimum temperature for MIB, geosmin and other volatile organic compounds. Temperatures higher than $65^{\circ} \mathrm{C}$ were not considered in this study because water vapor condensation on the fiber was observed at $65^{\circ} \mathrm{C}$, and this could damage the $\mathrm{GC} / \mathrm{MS}$. Ultimately, $65^{\circ} \mathrm{C}$ was selected as the optimum temperature.

The extraction time with SPME usually varies from a few minutes to an hour or more, depending on the matrix, analytes, fiber phase, and desired sensitivity. The extraction time did not greatly affect the total peak area (Table 1). For semi-volatile compounds, it takes longer time to achieve equilibrium than volatile compounds. The extraction efficiency slowly increased as the extraction time increased, and this trend was observed both in the total peak area (Fig. 2b) and for the four aliphatic analytes (Fig. 3b). No large differences were observed when the extraction time was between $20 \mathrm{~min}$ and $50 \mathrm{~min}$. The equilibrium time was $50 \mathrm{~min}$ or more, but routine analysis requires a short extraction time to maximize sample throughput. A proportional relationship has been demonstrated between the amount of analyte adsorbed into the SPME fiber and its initial concentration in the sample (Allard et al., 2012). Thus, an extraction time of $30 \mathrm{~min}$ was selected for quantification of the T\&O compounds in non-equilibrium conditions. This parameter setting was selected in consideration of the equilibrium time, and operational convenience as a compromise between sufficient extraction and a reasonable overall analysis time.

Increasing the desorption temperature decreased the partition coefficient of the analyte between the fiber coating and the gaseous phase. Using the highest possible temperature without damaging the fiber coating is a solution to minimize the desorption time of the analyte from the fiber (Sarafraz-Yazdi et al., 2011). The manufacturer recommends a maximum temperature of $270^{\circ} \mathrm{C}$ for the 2 $\mathrm{cm}-50 / 30 \mu \mathrm{m}$ CAR/PDMS/DVB fiber. Thus, the optimum desorption time was investigated at 1, 2, 3, 4 and 5 min at $270^{\circ} \mathrm{C}$. For the four aliphatic analytes, there were few differences in the studied desorption time range (Fig. 3c), but for the total peak area there were a sharp increase between 4 min and 5 min (Fig. 2c). Importantly, carryover was observed at $4 \mathrm{~min}$ or below. Consequently, $5 \mathrm{~min}$ was selected as the optimal time.

The stirring rate was another significant factor for SPME of the analytes (Table 1). The extraction efficiency will increase with stirring of the sample solution, which accelerates diffusion of the analytes from the water solution to the SPME fiber coating and reduces the extraction time (Sarafraz-Yazdi et al., 2011). However, rapid stirring tends to be uncontrollable and might cause poor measurement precision (Saito et al., 2008). The stirring rate affected each T\&O compound in similar way (Fig. 2d and Fig. 3d). The optimum extraction efficiencies for all 10 analytes were obtained with a stirring rate of $700 \mathrm{r} / \mathrm{min}$.
The $\mathrm{NaCl}$ content was also a highly significant factor (Table 1). In general, $\mathrm{NaCl}$ increases the ionic strength of the sample, and makes organic substances less soluble and increases the partition coefficients by the 'salting out' effect (Rianawati and Balasubramanian, 2009). By contrast, the total peak area decreased when the $\mathrm{NaCl}$ content was increased in this study (Fig. 2e). This could be caused by the $\mathrm{NaCl}$ increasing the sample viscosity, ionizing the analytes, and making them dissolve in the water solution (Sarafraz-Yazdi et al., 2011). However, we found that addition of $1 \mathrm{~g}$ of $\mathrm{NaCl}$ was good for the four aliphatic analytes, especially for cis-3-hexenyl acetate (Fig. 3e). Therefore, $1 \mathrm{~g}$ of $\mathrm{NaCl}$ was added in subsequent experiments to increase the extraction efficiencies of the four aliphatic analytes without greatly influencing the total peak area.

\subsection{Method evaluation}

In the preconcentration step, the optimal SPME conditions including fiber ( $2 \mathrm{~cm}-50 / 30 \mu \mathrm{m}$ DVB/CAR/PDMS), extraction temperature $\left(65^{\circ} \mathrm{C}\right)$, extraction time $(30 \mathrm{~min})$, desorption time $(5 \mathrm{~min})$, stirring rate $(700 \mathrm{r} / \mathrm{min})$ and $\mathrm{NaCl}$ content $(1 \mathrm{~g})$ were applied to the following water samples. Since the studied compounds are polar moleculars, like aldehydes, alcohols and esters, they were not well resolved with polysiloxane-based columns. Better separation was obtained on a polar column (DB-FFAP) than on a nonpolar column (DB-5MS). The optimized conditions gave good separation of the chromatographic peaks for all ten analytes, except for MIB and 2-methylbenzofuran (Fig. 4a). Nevertheless, quantification could be achieved with compound-specific target ions in the MS. The performance of the method with these conditions was investigated using standard aqueous solutions of the 10 analytes at different concentrations (1-1000 ng/L) (Table 2). Good linearity was observed for these substances and the correlation coefficients were found to exceed 0.9900 except for trans,trans-2,4-heptadienal (0.9898) at different ranges. The proposed method for more target compounds gave higher linear range and comparable or lower LODs compared with references (Table 3). For 8 of the 10 compounds with known OTCs, the LODs were near or below their OTCs. Moreover, apart from earthy and musty odor, the method can identify other odor-causing compounds. It is anticipated that the method could be expanded to incorporate more compounds that are associated with $\mathrm{T} \& \mathrm{O}$ problems in drinking water.

The precision of the method was evaluated by determination of the repeatability and reproducibility. Repeatability determinations involved measurement of 6 replicates consecutively while reproducibility determinations were 6 replicates over 3 different days. Considering of different linear ranges of different analytes, a low concentration $(50 \mathrm{ng} / \mathrm{L})$ and a high concentration (200 ng/L) were tested. Results in Table 4 showed good 
Table 2 Selected ions, linearity, determination coefficients, and limits of detection compared with odor threshold concentrations

\begin{tabular}{|c|c|c|c|c|c|}
\hline Compound & Selected ions & Linear range $(\mathrm{ng} / \mathrm{L})$ & $r^{2}$ & $\operatorname{LOD}(\mathrm{ng} / \mathrm{L})$ & OTC (ng/L) \\
\hline cis-3-Hexenyl acetate & $67^{\mathrm{a}}, 82$ & $1-200$ & 0.9977 & 6 & $1000-2000^{\mathrm{b}}$ \\
\hline IPMP & $137^{\mathrm{a}}, 152,124$ & $5-800$ & 0.9987 & 1 & $2-16^{\mathrm{c}}$ \\
\hline trans,trans-2,4-Heptadienal & $81^{\mathrm{a}}, 110,53$ & $100-1000$ & 0.9898 & 73 & $2500-5000^{\mathrm{d}}$ \\
\hline IBMP & $124^{\mathrm{a}}, 151,94$ & $1-1000$ & 0.9958 & 0.2 & $2-16^{\mathrm{c}}$ \\
\hline trans,cis-2,6-Nonadienal & $41^{\mathrm{a}}, 70,69$ & $50-1000$ & 0.9914 & 50 & $20^{\mathrm{d}}$ \\
\hline 2-Methylbenzofuran & $131^{\mathrm{a}}, 132,103$ & $1-1000$ & 0.9939 & 0.1 & Not available \\
\hline MIB & $95^{\mathrm{a}}, 108,135$ & $1-800$ & 0.9984 & 0.6 & $9-42^{\mathrm{c}}$ \\
\hline trans-2-Decenal & $41^{\mathrm{a}}, 55,70$ & $5-800$ & 0.9935 & 5 & Not available \\
\hline TCA & $195^{\mathrm{a}}, 167,210$ & $1-1000$ & 0.9915 & 0.2 & $0.1-2^{\mathrm{e}}$ \\
\hline Geosmin & $112^{\mathrm{a}}, 125,182$ & $1-1000$ & 0.9976 & 0.4 & $4-10^{\mathrm{c}}$ \\
\hline
\end{tabular}

${ }^{\text {a }}$ Target ions for quantitation; ${ }^{\mathrm{b}}$ Khiari et al., 1995; ${ }^{\mathrm{c}}$ Salemi et al., 2006; ${ }^{\mathrm{d}}$ Burlingame et al., 1992; ${ }^{\mathrm{e}}$ Zhang et al., 2005.

Table 3 Comparison of analytical method, linearity, and LODs of T\&O compounds

\begin{tabular}{|c|c|c|c|c|}
\hline $\mathrm{T} \& \mathrm{O}$ compounds & $\begin{array}{l}\text { Number of } \\
\text { analytes }\end{array}$ & Performance & Analytical method & References \\
\hline Geosmin, MIB, IPMP, TCA, IBMP & 5 & $\begin{array}{l}\text { Linearity: } 1-500 \mathrm{ng} / \mathrm{L} \\
\text { LOD: } 0.34-0.59 \mathrm{ng} / \mathrm{L}\end{array}$ & SPME-GC/MS & Sung et al., 2005 \\
\hline Geosmin, MIB, IPMP, IBMP, TCA & 5 & $\begin{array}{l}\text { Linearity: } 1-200 \mathrm{ng} / \mathrm{L} \text {; } \\
\text { LOD: } 0.5-1.5 \mathrm{ng} / \mathrm{L}\end{array}$ & SPME-GC/MS & Sun et al., 2012 \\
\hline $\begin{array}{l}\text { Geosmin, MIB, IPMP, IBMP, TCA, anisole, } \\
\text { trans, trans-2,4-heptadienal }\end{array}$ & 7 & $\begin{array}{l}\text { Linearity: } 1-500 \mathrm{ng} / \mathrm{L} \text {; } \\
\text { LOD: } 0.1-1 \mathrm{ng} / \mathrm{L}\end{array}$ & $\begin{array}{l}\text { Liquid-liquid } \\
\text { extraction-GC/MS }\end{array}$ & Shin and Ahn, 2004 \\
\hline $\begin{array}{l}\text { Dimethylsulfide, dimethyltrisulfide, } \\
\text { MIB, geosmin, IPMP, IBMP, } \\
\beta \text {-ionone, } \beta \text {-cyclocitral }\end{array}$ & 8 & $\begin{array}{l}\text { Linearity: } 1-500 \mathrm{ng} / \mathrm{L} \\
\text { LOD: } 0.3-1.1 \mathrm{ng} / \mathrm{L}\end{array}$ & P\&T-GC/MS & Chen et al., 2010a \\
\hline $\begin{array}{l}\text { Geosmin, MIB, IPMP, IBMP, } \beta \text {-ionone, } \\
\beta \text {-cyclocitral, dimethylsulfide, } \\
\text { dimethyltrisulfide }\end{array}$ & 8 & $\begin{array}{l}\text { Linearity: } 1-500 \mathrm{ng} / \mathrm{L} \\
\text { LOD: } 0.08-1.5 \mathrm{ng} / \mathrm{L}\end{array}$ & P\&T-GC/MS & Deng et al., 2011 \\
\hline $\begin{array}{l}\text { Geosmin, MIB, IPMP, IBMP, TCA, 2-methylbenzofuran, } \\
\text { cis-3-hexenyl acetate, trans, cis -2,6-nonadienal, } \\
\text { trans-2-decenal, trans, trans-2,4-heptadienal }\end{array}$ & 10 & $\begin{array}{l}\text { Linearity: } 1-1000 \mathrm{ng} / \mathrm{L} \\
\text { LOD: } 0.1-73 \mathrm{ng} / \mathrm{L}\end{array}$ & SPME-GC/MS & This study \\
\hline
\end{tabular}

Table 4 Accuracy and precision of the method

\begin{tabular}{|c|c|c|c|c|c|c|}
\hline \multirow[t]{2}{*}{ Compound } & \multicolumn{2}{|c|}{ Repeatability $(\mathrm{RSD} \%)(n=6)$} & \multicolumn{2}{|c|}{ Reproducibility (RSD $\%)(n=6)$} & \multicolumn{2}{|c|}{ Recovery $(\%)(n=3)$} \\
\hline & $50 \mathrm{ng} / \mathrm{L}$ & $200 \mathrm{ng} / \mathrm{L}$ & $50 \mathrm{ng} / \mathrm{L}$ & $200 \mathrm{ng} / \mathrm{L}$ & Tap water & Surface water \\
\hline cis-3-Hexenyl acetate & 8.57 & 10.52 & 14.43 & 11.39 & $142.96 \pm 12.36$ & $157.95 \pm 19.81$ \\
\hline IPMP & 8.92 & 6.94 & 9.20 & 4.36 & $96.68 \pm 10.57$ & $99.86 \pm 12.32$ \\
\hline trans,trans-2,4-Heptadienal & 13.32 & 14.34 & 21.41 & 16.16 & $92.80 \pm 5.48$ & $94.86 \pm 18.46$ \\
\hline IBMP & 8.16 & 6.89 & 7.82 & 4.81 & $85.99 \pm 13.90$ & $87.64 \pm 11.59$ \\
\hline trans,cis-2,6-Nonadienal & 10.39 & 8.22 & 6.62 & 5.70 & $133.63 \pm 5.84$ & $128.50 \pm 11.19$ \\
\hline 2-Methylbenzofuran & 14.75 & 12.67 & 14.14 & 15.25 & $84.16 \pm 3.77$ & $105.05 \pm 13.74$ \\
\hline MIB & 14.30 & 8.05 & 20.78 & 15.91 & $101.56 \pm 12.30$ & $112.30 \pm 13.18$ \\
\hline trans-2-Decenal & 13.47 & 8.77 & 21.41 & 9.62 & $76.88 \pm 5.11$ & $117.61 \pm 16.71$ \\
\hline TCA & 10.47 & 9.78 & 15.57 & 7.95 & $74.63 \pm 2.52$ & $85.86 \pm 12.47$ \\
\hline Geosmin & 9.11 & 6.19 & 8.21 & 6.61 & $98.68 \pm 17.08$ & $90.29 \pm 9.63$ \\
\hline
\end{tabular}

repeatability ranging from $6.89 \%$ to $14.75 \%$ for both concentrations. The reproducibility was still acceptable ranging from $4.36 \%$ to $16.16 \%$ for almost all the analytes at both concentrations. However, the reproducibility of trans,trans-2,4-heptadienal (21.41\%), MIB (20.78\%) and trans-2-decenal $(21.41 \%)$ was relatively higher at $50 \mathrm{ng} / \mathrm{L}$ because of the polarity of the carbonyl group or hydroxyl group. Future work should consider the additional use of a suitable internal standard to increase the precision of the method.

For real water samples, matrix effects need to be investigated and controlled. The accuracy of the method for determination of real water samples was evaluated by measuring the recovery $(R, \%)$ of each analyte in tap water and surface water spiked with a concentration $100 \mathrm{ng} / \mathrm{L}$ (in triplicate). Recovery was calculated as:

$R=\frac{C_{\text {spiked sample }}-C_{\text {sample }}}{C_{\text {spiking standard }}} \times 100 \%$

Good recoveries (84.16\%-117.61\%) were obtained for most of the analytes both in tap water and surface water, indicating that matrix effects were negligible using this method, and thus quantification could be done by external calibration in drinking water analysis. However, the recovery of TCA $(74.63 \%$ in tap water and $85.86 \%$ in surface 

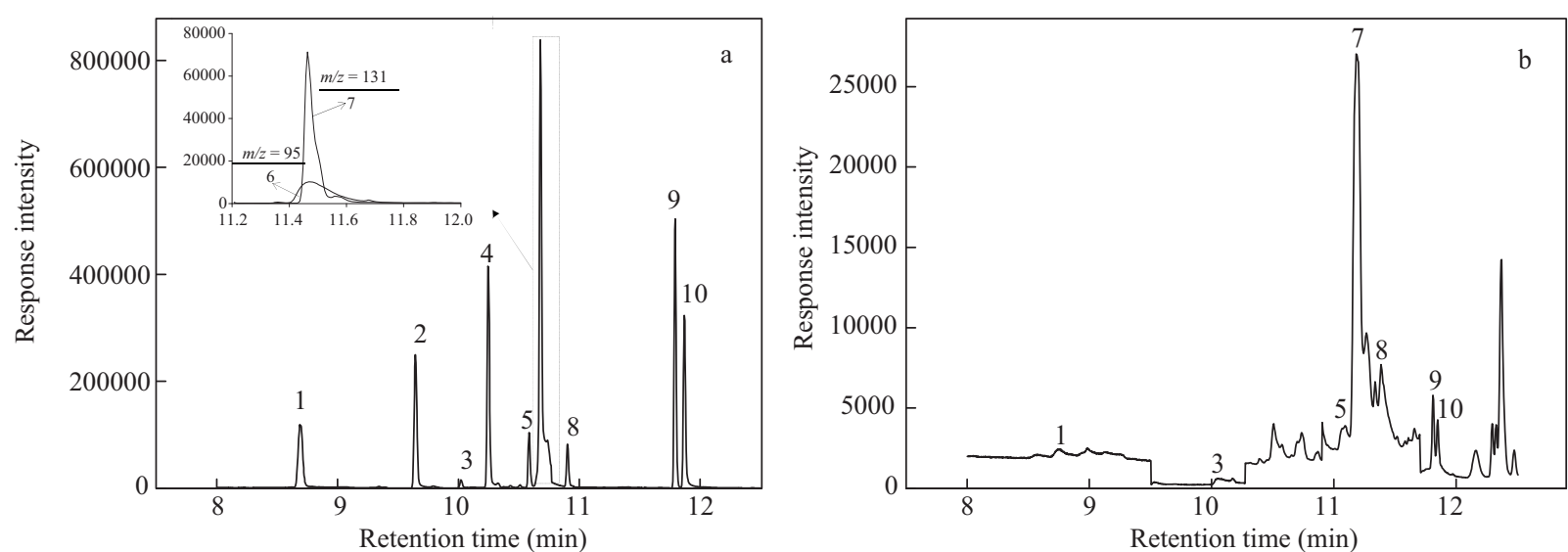

Fig. 4 Selected ion chromatogram of standard solution (a) and real water sample (b) for 10 T\&O compounds using optimized conditions. Compounds in order are as follows: peak (1) cis-3-hexenyl acetate, (2) IPMP; (3) trans,trans-2,4-heptadienal; (4) IBMP; (5) trans,cis-2,6-nonadienal; (6) 2methylbenzofuran (7) MIB; (8) trans-2-decenal; (9) TCA; (10) geosmin.

water) was relatively lower. Zhang et al. (2005) also obtained lower recoveries of haloanisole (about 60\%) than those of geosmin and MIB (above $80 \%$ ). The recoveries of cis-3-hexenyl acetate and trans,cis-2,6-nonadienal were a little bit higher than the other compounds, especially cis3-hexenyl acetate. The higher recovery of cis-3-hexenyl acetate might be explained that the ester bond of cis-3hexenyl acetate could be hydrolyzed at low concentrations.

\subsection{Occurence, concentration and possible influence factor of $T \& O$ compounds in real water sample}

The developed SPME-GC/MS method was applied to identify and quantify $\mathrm{T} \& \mathrm{O}$ compounds in source water, treatment process water and tap water collected from Lianyungang. In Fig. 4b, a chromatogram for a real water sample was shown. The concentration levels of these compounds (Table 5) ranged from not detected (n.d.) to several nanograms per liter or hundreds of nanograms per liter. In surface water, MIB and geosmin concentration ranged from 3.2 to $51.8 \mathrm{ng} / \mathrm{L}$ and 13.4 to $26.7 \mathrm{ng} / \mathrm{L}$, respectively. It was comparable with the published total concentrations of geosmin and MIB in the 8 water samples from Gonghu Bay of Lake Taihu ranged from 0 to $11.29 \mathrm{ng} / \mathrm{L}$ and 0 to $18.69 \mathrm{ng} / \mathrm{L}$, respectively (Chen et al., 2010a). The only one of the nine investigated sites in Qinhuangdao was shown geosmin production, however, the peak geosmin concentration exceeding $7000 \mathrm{ng} / \mathrm{L}$ was detected in July 2007 (Yu et al., 2009). The MIB and geosmin in surface water from Qiangwei River were detected; however, the causes needed further investigation.

Another earthy and musty compound TCA was found at concentrations (from 12.2 to $195.9 \mathrm{ng} / \mathrm{L}$ ) which were significantly higher than its OTC $(0.1-2 \mathrm{ng} / \mathrm{L})$. IBMP and IPMP are two kinds of pyrazines compounds that produce vegetable odor and vegetable to decaying odor, respectively. IBMP was described to be formed during microbial degradation of grass under anaerobic conditions, while IPMP was known to be a product of soil organ-

Table 5 Concentrations of $10 \mathrm{~T} \& \mathrm{O}$ compounds in real water samples (unit: ng/L)

\begin{tabular}{|c|c|c|c|c|c|c|c|c|c|c|c|}
\hline $\begin{array}{l}\text { Sampling } \\
\text { sites }\end{array}$ & & $\begin{array}{r}\text { cis-3-Hexenyl } \\
\text { acetate }\end{array}$ & IPMP & $\begin{array}{r}\text { trans, } \\
\text { trans }-2,4- \\
\text { Heptadienal }\end{array}$ & IBMP & $\begin{array}{r}\text { trans, } \\
\text { cis-2,6- } \\
\text { Nonadienal }\end{array}$ & $\begin{array}{l}\text { 2-Methyl- } \\
\text { benzofuran }\end{array}$ & MIB & trans-2-Decenal & TCA & Geosmin \\
\hline \multirow{7}{*}{$\begin{array}{l}\text { Surface } \\
\text { water }\end{array}$} & $\mathrm{a}$ & 4.2 & n.d. & 437.5 & 31.4 & 153.5 & 199.0 & 3.7 & 36.1 & 122.3 & 20.4 \\
\hline & $\mathrm{b}$ & 4.0 & n.d. & 242.0 & n.d. & 183.8 & 10.9 & 10.0 & 19.3 & 12.2 & 13.6 \\
\hline & $\mathrm{c}$ & 3.9 & n.d. & 316.9 & 17.7 & 257.9 & 33.0 & 3.2 & 5.3 & 24.8 & 14.4 \\
\hline & $\mathrm{d}$ & 4.1 & n.d. & 324.0 & n.d. & 180.6 & 23.6 & 51.8 & 38.7 & 18.6 & 13.4 \\
\hline & $\mathrm{e}$ & 3.9 & n.d. & 127.4 & n.d. & 83.5 & 14.4 & 17.6 & 21.0 & 14.0 & 13.5 \\
\hline & $\mathrm{f}$ & 4.1 & n.d. & 313.7 & 19.7 & 131.2 & 158.2 & 3.5 & 126.2 & 77.9 & 17.9 \\
\hline & $\mathrm{g}$ & 4.1 & 7.6 & 145.6 & 44.4 & 195.4 & 289.8 & 4.1 & 308.3 & 195.9 & 26.7 \\
\hline \multirow{4}{*}{$\begin{array}{l}\text { Treatment } \\
\text { process } \\
\text { water }\end{array}$} & $\mathrm{h}$ & 4.0 & n.d. & 364.0 & 17.9 & 97.7 & 70.7 & 2.8 & 98.6 & 35.0 & 16.3 \\
\hline & $\mathrm{i}$ & 4.2 & n.d. & 377.2 & 15.5 & 50.5 & 23.1 & 3.2 & 22.8 & 17.0 & 14.2 \\
\hline & $\mathrm{j}$ & 3.8 & n.d. & 118.1 & 17.6 & 77.3 & 59.4 & 3.0 & 15.7 & 31.3 & 13.5 \\
\hline & $\mathrm{k}$ & 4.3 & n.d. & 434.3 & 20.3 & 84.4 & 96.3 & 4.8 & 220.5 & 59.8 & 16.5 \\
\hline Tap & 1 & 4.3 & n.d. & 340.1 & 16.6 & 103.3 & 20.8 & 3.5 & 15.0 & 15.9 & 13.2 \\
\hline \multirow[t]{2}{*}{ water } & $\mathrm{m}$ & 12.5 & 6.8 & 353.0 & 39.1 & 190.1 & 176.1 & 6.8 & 112.8 & 122.3 & 24.5 \\
\hline & $\mathrm{n}$ & 4.8 & n.d. & 353.0 & 18.9 & 79.9 & 21.6 & 2.9 & 18.2 & 17.1 & 14.3 \\
\hline
\end{tabular}

a-g are surface water samples; n.d.: not detected.

Treatment processes are: (h) settled water, (i) filtered water, (j) ozonated water, and (k) finished water. 
isms (actinomycetes) and has been found in many food and water samples (Khiari et al., 1997). In the current study, an equally low concentration of IPMP was detected in only site $(\mathrm{g})$ with concentration at $7.6 \mathrm{ng} / \mathrm{L}$, IBMP concentrations are between n.d. and $44.4 \mathrm{ng} / \mathrm{L}(\mathrm{g})$. This result is different from previous report by Chen et al. (2010a). It is certain that IPMP concentration was too low to produce odor during the studied period. Earthy and musty compounds such as MIB, geosmin, IPMP and IBMP are of major concern in previous $\mathrm{T} \& \mathrm{O}$ studies because of their extremely low OTCs (Sun et al., 2012). Interestingly, the dominant T\&O compounds were trans,trans-2,4heptadienal, trans,cis-2,6-nonadienal, trans-2-decenal and 2-methylbenzofuran in this study, not the most investigated earthy and musty compounds MIB or geosmin. In particular, the fishy compound trans,trans-2,4-heptadienal was present at the highest concentration levels (127.4 to 437.5 $\mathrm{ng} / \mathrm{L}$ ), which corresponded with the fishy smell we noted for the suspended solid particles on the filter membrane. The dominant odorous compounds in this study have received less attention before now probably because their OTCs are so high that they were overlooked as major T\&O compounds. During this study period, cis-3-hexenyl acetate was not significant.

In treatment water, surface water $(\mathrm{g})$ was the source water of the studied waterworks in Lianyungang, on the downstream of the Qiangwei River. Thus, that is why several compounds such as 2-methylbenzofuran, trans-2decenal and TCA in source water $(\mathrm{g})$ were at the highest concentration level among the surface water samples. Conventional treatment (sedimentation (h) and filtration (i)) combined with advanced treatment ozone-BAC (j) was used. Chlorine was applied in the finished water (k). As is commonly believed, conventional treatment is ineffective in controlling $\mathrm{T} \& \mathrm{O}$ compounds. However, effective IPMP, IBMP, trans,cis-2,6-nonadienal, 2methylbenzofuran, trans-2-decenal, and TCA removal was demonstrated by sedimentation and filtration in this study. It is strange that the unsaturated aldehydes trans,trans-2,4heptadienal seemed to be reduced by advanced treatment but rose again in finished water. The treatment processes had no significant effect on cis-3-hexenyl acetate, MIB and geosmin. These have been demonstrated that dissolved odorous compounds are affected by various factors, such as rate of odor production by algal cells, biodegradation by microbes, photolysis by sunlight, absorption by particles, disturbance by wave and volatilisation of odorous compounds themselves.

The analytes also existed in tap water. The TCA concentrations and the trans,cis-2,6-nonadienal concentrations were over 10 times higher than their OTCs. This is a more serious problem because T\&O problems generated in distribution system are directly delivered to the customers. Sample (l) and (m) maintained almost stable or lower concentration levels compared with the finished water $(\mathrm{k})$. However, an increase was obtained in the middle of the pipeline at point $(\mathrm{m})$ for all analytes. For 2-methylbenzofuran, trans-2-decenal and TCA, the concentrations were almost 10 times higher than the other two tap water samples. A possible explanation is that it was resulted from leaching plastic pipes or microbial activity in the distribution system (Peter and von Gunten, 2009). However, the causes needed further investigations to confirm it. Anyway, the water distribution network cannot be ignored as a $\mathrm{T} \& \mathrm{O}$ compounds source.

\section{Conclusions}

In the present study, $10 \mathrm{~T} \& \mathrm{O}$ compounds were simultaneously determined using HS-SPME-GC/MS. The best fiber for extracting $\mathrm{T} \& \mathrm{O}$ compounds with different polarities for non-target compound screening was $2 \mathrm{~cm}-50 / 30 \mu \mathrm{m}$ DVB/CAR/PDMS. It should be noted that the method enabled LODs $(0.1-73 \mathrm{ng} / \mathrm{L})$ of the analytes below or close to their OTCs. Therefore, the method can be used by utilities to quickly and reliably detect $\mathrm{T} \& \mathrm{O}$ compounds and determine their concentrations before consumers can detect objectionable tastes and odors in drinking water. These compounds are widely detected in surface water and removed in water treatment process varying with compounds. In addition, T\&O compounds exceeding OTCs in distribution systems posed a more serious problem to the customers.

\section{Acknowledgments}

This work was supported by the National Natural Science Foundation of China (No. 21007077, 51290283) and the Ministry of Water Resources' Special Funds for Scientific Research on Public Causes (No. 201201032).

\section{Supporting materials}

Supplementary data associated with this article can be found in the online version.

\section{References}

Allard S, Charrois J W A, Joll C A, Heitz A, 2012. Simultaneous analysis of 10 trihalomethanes at nanogram per liter levels in water using solid-phase microextraction and gas chromatography mass-spectrometry. Journal of Chromatography A, 1238: 15-21.

Burbank H M, Qian M C, 2005. Volatile sulfur compounds in Cheddar cheese determined by headspace solid-phase microextraction and gas chromatograph-pulsed flame photometric detection. Journal of Chromatography A, 1066(12): $149-157$.

Burlingame G A, Muldowney J J, Maddrey R E, 1992. Cucumber flavor in Philadelphia's drinking water. Journal American Water Works Association, 84(8): 92-97.

Cancho B, Ventura F, Galceran M T, 2002. Determination of 
aldehydes in drinking water using pentafluorobenzylhydroxylamine derivatization and solid-phase microextraction. Journal of Chromatography A, 943(1): 1-13.

Chen J M, Xie P, Ma Z M, Niu Y, Tao M, Deng X W et al., 2010a. A systematic study on spatial and seasonal patterns of eight taste and odor compounds with relation to various biotic and abiotic parameters in Gonghu Bay of Lake Taihu, China. Science of the Total Environment, 409(2): 314-325.

Chen J M, Zou J, Zeng J B, Song X H, Ji J J, Wang Y R et al., 2010b. Preparation and evaluation of graphene-coated solid-phase microextraction fiber. Analytica Chimica Acta, 678(1): 44-49.

Deng X W, Liang G D, Chen J, Qi M, Xie P, 2011. Simultaneous determination of eight common odors in natural water body using automatic purge and trap coupled to gas chromatography with mass spectrometry. Journal of Chromatography A, 1218(24): 3791-3798.

Fang F, Hong C S, Chu S, Kou W, Bucciferro A, 2003. Reevaluation of headspace solid-phase microextraction and gas chromatography-mass spectrometry for the determination of methyl tert-butyl ether in water samples. Journal of Chromatography A, 1021(1-2): 157-164.

George P M, Raghunath B K, Manocha L M, Warrier A M, 2004. EDM machining of carbon-carbon composite-a Taguchi approach. Journal of Materials Processing Technology, 145(1): 66-71.

Gioacchini A M, Menotta M, Bertini L, Rossi I, Zeppa S, Zambonelli A et al., 2005. Solid-phase microextraction gas chromatography/mass spectrometry: a new method for species identification of truffles. Rapid Communications in Mass Spectrometry, 19(17): 2365-2370.

Godayol A, Alonso M, Besalú E, Sanchez J M, Anticó E, 2011. Odour-causing organic compounds in wastewater treatment plants: Evaluation of headspace solid-phase microextraction as a concentration technique. Journal of Chromatography A, 1218(30): 4863-4868.

Graham J L, Loftin K A, Meyer M T, Ziegler A C, 2010. Cyanotoxin mixtures and taste-and-odor compounds in cyanobacterial blooms from the Midwestern United States. Environmental Science and Techonology, 44(19): 73617368.

Hartvigsen K, Lund P, Hansen L F, Hølmer G, 2000. Dynamic headspace gas chromatography/mass spectrometry characterization of volatiles produced in fish oil enriched mayonnaise during storage. Journal of Agricultural and Food Chemistry, 48(10): 4858-4867.

Khiari D, Suffet I H, Barrett S E, 1995. Extraction and identification of chemicals causing grassy odors in Flavor Profile Analysis (FPA) reference standards. Water Science and Technology, 31(11): 93-98.

Khiari D, Barrett S E, Suffet I H, 1997. Sensory GC analysis of decaying vegetation and septic odors. Journal American Water Works Association, 89(4): 150-161.

Li X, Li C M, Chen J M, Li C L, Sun C, 2008. Polythiophene as a novel fiber coating for solid-phase microextraction. Journal of Chromatography A, 1198-1199: 7-13.

Magan N, Evans P, 2000. Volatiles as an indicator of fungal activity and differentiation between species, and the potential use of electronic nose technology for early detection of grain spoilage. Journal of Stored Products Research, 36(4): 319-
340.

Malleret L, Bruchet A, Hennion M, 2001. Picogram determination of "earthy-musty" odorous compounds in water using modified closed loop stripping analysis and large volume injection GC/MS. Analytical Chemistry, 73(7): 1485-1490.

Morita K, Kubota K, Aishima T, 2002. Investigating sensory characteristics and volatile components in boiled scallop aroma using chemometric techniques. Food Chemistry, 78(1): 39-45.

Ochiai N, Sasamoto K, Takino M, Yamashita S, Daishima S, Heiden A et al., 2001. Determination of trace amounts of off-flavor compounds in drinking water by stir bar sorptive extraction and thermal desorption GC-MS. Analyst, 126(10): 1652-1657.

Palmentier J P F P, Taguchi V Y, 2001. The determination of six taste and odour compounds in water using Ambersorb 572 and high resolution mass spectrometry. Analyst, 126(6): 840-845.

Peter A, Köster O, Schildknecht A, von Gunten U, 2009. Occurrence of dissolved and particle-bound taste and odor compounds in Swiss lake waters. Water Research, 43(8): 2191-2200.

Peter A, von Gunten U, 2009. Taste and odour problems generated in distribution systems: A case study on the formation of 2,4,6-trichloroanisole. Journal of Water Supply Research and Technology-AQUA, 58(6): 386-394.

Proulx F, Rodriguez M J, Sérodes J B, Bouchard C, 2012. Spatiotemporal variability of tastes and odors of drinking water within a distribution system. Journal of Environmental Management, 105: 12-20.

Rianawati E, Balasubramanian R, 2009. Optimization and validation of solid phase micro-extraction (SPME) method for analysis of polycyclic aromatic hydrocarbons in rainwater and stormwater. Physics and Chemistry of the Earth, Parts $A / B / C, 34(13-16): 857-865$.

Saito K, Okamura K, Kataoka H, 2008. Determination of musty odorants, 2-methylisoborneol and geosmin, in environmental water by headspace solid-phase microextraction and gas chromatography-mass spectrometry. Journal of Chromatography A, 1186(1-2): 434-437.

Salemi A, Lacorte S, Bagheri H, Barceló D, 2006. Automated trace determination of earthy-musty odorous compounds in water samples by on-line purge-and-trapgas chromatography-mass spectrometry. Journal of Chromatography A, 1136(2): 170-175.

Sarafraz-Yazdi A, Mosadegh M, Amiri A, 2011. Determination of volatile organic compounds in environmental water samples using three solid-phase microextraction fibers based on sol-gel technique with gas chromatography-flame ionization detector. Analytical Methods, 3(8): 1877-1886.

Shin H S, Ahn H S, 2004. Simple, rapid, and sensitive determination of odorous compounds in water by GC-MS. Chromatographia, 59(1-2): 107-113.

Srinivasan R, Sorial G A, 2011. Treatment of taste and odor causing compounds 2-methyl isoborneol and geosmin in drinking water: A critical review. Journal of Environmental Sciences, 23(1): 1-13.

Suffet I H M, Schweitze L, Khiari D, 2004. Olfactory and chemical analysis of taste and odor episodes in drinking water supplies. Reviews in Environmental Science and 
Bio/Technology, 3(1): 3-13.

Sun W F, Jia R B, Gao B Y, 2012. Simultaneous analysis of five taste and odor compounds in surface water using solid-phase extraction and gas chromatography-mass spectrometry. Frontiers of Environmental Science and Engineering, 6(1): 66-74.

Sung Y, Li T, Huang S, 2005. Analysis of earthy and musty odors in water samples by solid-phase microextraction coupled with gas chromatography/ion trap mass spectrometry. $T a$ lanta, 65(2): 518-524.

Vichi S, Pizzale L, Conte L S, Buxaderas S, López-Tamames E, 2005. Simultaneous determination of volatile and semivolatile aromatic hydrocarbons in virgin olive oil by headspace solid-phase microextraction coupled to gas chromatography/mass spectrometry. Journal of Chromatography $A, 1090$ (1-2): 146-154.

Watson S B, Brownlee B, Satchwill T, Hargesheimer E E, 2000. Quantitative analysis of trace levels of geosmin and MIB in source and drinking water using headspace SPME. Water Research, 34(10): 2818-2828.

Watson S B, Satchwill T, Dixon E, Mccauley E, 2001. Under-ice blooms and source-water odour in a nutrient-poor reservoir: biological, ecological and applied perspectives. Freshwater
Biology, 46(11): 1553-1567.

Yang M, Yu J, Li Z, Guo Z, Burch M, Lin T F, 2008. Taihu Lake not to blame for Wuxi's woes. Science, 319(5860): 158.

Young C C, Suffet I H, Crozes G, Bruchet A, 1999. Identification of a woody-hay odor-causing compound in a drinking water supply. Water Science and Technology, 40(6): 273-278.

Yu J W, Zhao Y M, Yang M, Lin T F, Guo Z H, Gu J N et al., 2009. Occurrence of odour-causing compounds in different source waters of China. Journal of Water Supply Research and Technology-AQUA, 58(8): 587-594.

Zander A K, Pingert P, 1997. Membrane-based extraction for detection of tastes and odors in water. Water Research, 31(2): 301-309.

Zhang L F, Hu R K, Yang Z G, 2005. Simultaneous picogram determination of "earthy-musty" odorous compounds in water using solid-phase microextraction and gas chromatographymass spectrometry coupled with initial cool programmable temperature vaporizer inlet. Journal of Chromatography A, 1098(1-2): 7-13.

Zhang X J, Chen C, Ding J Q, Hou A X, Li Y, Niu Z B et al., 2010. The 2007 water crisis in Wuxi, China: Analysis of the origin. Journal of Hazardous Materials, 182(1-3): 130135 . 